\title{
Developing Conceptual frame work for building Sustainable Organisation through Organisational Citizenship Behaviour
}

\author{
Ramalakshmi Krishnan, Anil Chandrasekaran, Selvarani \\ Mariappan
}

\begin{abstract}
The study examined the existing literature on Organisational Citizenship Behaviour $(\mathrm{OCB})$ and its associated variables through social network analysis using Gephi. A sample of 22 recent research articles related to $O C B$ and the variables and constructs used in those studies have been selected for network analysis to identify the major influencing variables and to identify possible research gaps to formulate a conceptual model for further research. GEPHI 0.9.2 and NodeXL graph softwares were used for the network analysis to enable easy visualisation of the links between the variables. The result shows that $O C B$ and commitment, $O C B$ and Job satisfaction, $O C B$ and empowerment were most examined however, the most prominent variables altruism, conscientiousness, sportsmanship that form a part of the OCB have not been used.
\end{abstract}

Keywords: Organisational citizenship Behaviour, Network analysis, Graph Theory.

\section{INTRODUCTION}

In today's knowledge based competitive world employee contribution plays a vital role for the success and sustainability of any organisation. Innovation and technological changes disrupt the existing business model and employees engage in Intrapreneurial activities. Employees are expected to display a set of voluntary behaviours i.e., Organisational Citizenship Behaviour which are not part of the official duties of the individual, but improve the organizational role. Organisational citizenship Behaviour has been examined since 1970s and in the past decade, there has been a considerable research in studying this behaviouras it is becoming an imperative to understand the employee as an integral part of the organisational movement. One reason could be due to the ability of mobility in workforces across borders thus making the organisation a plethora of diverse people with varying backgrounds and skills.

Citizenship Behaviour has been commonly associated to hierarchical adequacy and this kind of representative practices have significant outcomes in the working environment. organisational Citizenship Behaviour (OCB) is a term that encompasses anything positive and

Revised Manuscript Received on December 09, 2019.

* Correspondence Author

Ramalakshmi Krishnan *, Research scholar, Kalasalingam Business School, Kalasalingam Academy of Research and Education, Krishnan Koil , Tamil Nadu India , Email.iamlakshmimba@gmail.com

Anil Chandrasekaran, Higher Colleges of Technology, Dubai, United Arab Emirates, achandrasekaran@hct.ac.ae.

Selvarani Mariappan, Department of Business Administration Kalasalingam Business School, Kalasalingam Academy of Research and Education, Krishnan Koil, Tamil Nadu India, selvarani@klu.ac.in

accommodating that employee do, of their own will, which supports partners and points of interest the association.

Ordinarily, representatives who more often than not partake in OCB may not by and large be the top performers (anyway they could be, as errand execution is likewise related to $\mathrm{OCB}$ ), yet they are the ones who are known to 'go the extra mile' or 'go well past' the base endeavours required to complete a simply agreeable occupation. Organisational citizenship behaviour (OCB) has accumulated much scholastic consideration since its origination. It is seen to be something elusive; OCB isn't in every case formally perceived or remunerated, and ideas like 'support' or 'kind disposition' are additionally hard to measure. This concept rose in light of the acknowledgment that solitary taking a glimpse at employment explicit work practices overlooked a critical segment of the activity space. Initially, specialists in this field concentrated distinctly on trainings at it straightforwardly encouraged the yield of the association. As the movement publicize ended up being dynamically intense, it wound up significant for labourers to go well past which is officially required by the normal arrangement of duties in order to remain centered.

The use of social network analysis (SNA) as a methodology enables the easy visualisation of the connections thus enabling better analysis of the links to the variables in the literatures. SNA is rather a contemporary tool that has seen exponential groeth over the last decade. Based on graph theory the tool helps in analysing dyadic relationships both directed and undirected. The analysis of the links of the various constructs are better analysed using such tools to review and identify the variables. The main purpose of this study is to examine the factors/variables associated with OCB through existing literature and identify the research gap and formulate a conceptual model for future research which is best accomplished using this versatile tool. equations, graphics, and tables are not prescribed, although the various table text styles are provided. The formatter will need to create these components, incorporating the applicable criteria that follow.

\section{REVIEW OF LITERATURE}

The study has used 22 recent reseraches in this field that are discussed in brief. The term Organizational Citizenship Behavior (OCB) was instituted by Bateman and Organ (1983 in their research and later they described $\mathrm{OCB}$ as an individual discretionary 
behaviour which is not recognised by the organisation through its reward system but promotes the effective functioning of organisations. It was further identified that OCB positively promotes to maintain organisational social system (Bateman and Organ, 1983; Podsakoff et al., 1990). Organ (1988) expounds the following five explicit classes of discretionary behaviour and the commitment of each to effectiveness:.

(1) Altruism is coordinated in the direction of different people, yet adds to amass effectiveness by upgrading person's exhibition; members help new associates and give unreservedly of their time.

(2) Conscientiousness is the mindful application of time to upgrade the proficiency of the two persons and the gathering; members contribute more opportunity to the association what's more, apply exertion past the official requirements.

(3) Sportsmanship constructs the degree of time spent on hierarchical undertakings; adherents decline time spent on whimpering, grumbling and griping.

(4) Civility neutralizes issues and empowers accommodating use of time; individuals give early notices, advantageous updates and fitting information.

(5) Civic ideals advances the interests of the association extensively; members deliberately serve on boards also, go to capacities.

Anne Kariuki, and Kellen Kiambati, (2017) research adopted a quantitative approach and the survey was undertaken in a manufacturing firm in Kenya. Their study analysed the connection among empowerment and firm performance by choosing employee commitment as a arbitrating variable and OCB as a curbing variable. The result revealed that only employee empowerment has a positive significant influence on firm's performance and organizational commitment mediated this relationship but OCB moderating effect is not significant.

Asaph Katarangi Kaburur, (2011) studied the affiliation among Competencies, Empowerment and Organizational Citizenship Behaviors (OCBs) among public sector accountants. A cross sectional survey design was used basing on the sample size of 86 respondents who were certified public sector accountants from Uganda government ministries. The study emphasized the relationship between competencies, empowerment and found there is no critical connection between competences, empowerment and OCB.

Gülsevim Yumuk Günay (2018) considered the association between job satisfaction, OCB and EP. By collecting data from 134 public employees as a sample the researcher analysed whether these variables differed by demographic characteristics. The result revealed that the job satisfaction differs on demographic variables and it affects the organizational citizenship behaviour and in turn OCB affects employee performance.:
Jency Priyadharshany and Sujath. (2017) developed the modelled the direct and indirect effect of structural and psychological empowerment on OCB. This study wasundertaken by taking a convenience sample size of 326 respondents working in private universities which provide engineering courses. They found that the working environment, intrinsic motivation and inner motivation promote citizenship behaviour. Empowered environment creates organisational citizenship conduct.

Lara Priyadharshini Sinnappan, and Mahadevan Amulraj, (2014) examined the influence of selected HR practices i.e. Rewards and Recognition, Empowerment on OCB and its importance between qualified engineers. Four dimensions of OCB were included in this study with all the four components of organisational citizenship conduct. It implies at the point when workers get rewards and acknowledgment from their organisation, they will feel appreciative to react with more elevated amounts of commitment. There is a critical relationship in empowerment with loyalty which is the one of the dimension of organizational citizenship behaviour. This study has demonstrated that the worker's organisational citizenship behaviour is persevered at the point when there is a countless level of rewards and recognition in the organisation associated to empowerment.

Mirza Muhammad Azeem et.al (2005) investigated the connections among organisational equity, mental empowermnet, hierarchical citizenship conduct, and saw authoritative execution. For this reason, the information was gathered from 260 representatives working in various banks in Pakistan. Nobleman and Kenny's relapse approach was utilized to test the intercession impact. The investigation uncovered that organisational citizenship conduct halfway intervened the connection between hierarchical equity and saw hierarchical execution. They discovered that organisational citizenship conduct completely intervened the connection between psychological empowerment and saw authoritative execution.

Muhammad Ehsan Malik, et.al, (2012) examined the extent of leadership and personality traits affect the organizational citizenship. It was conducted among the banking sector of Pakistan in several cities of Punjab province. The result revealed that the leadership potentials and positive behaviour traits suggestively enhance Organizational Citizenship Behaviour.

Pratami Wulan Tresna (2016) studied the direct and indirect effects of execution of transformational leadership and job fulfilment conditions on OCB. Data was conducted by taking stratified proportionate random sample of 59 lecturers working in three universities at Tasikmalaya. The level of reaction for statements regarding job satisfaction is deemed under extraordinary category. It has also been revealed that the respondents' response on statements regarding organizational citizenship behaviour is great. Leadership directly influenced by OCB. 
Rahil Kazemi Talachi, et.al, (2013) conducted research among the workers of the Golestan Province industry, mine and trade organisation (Iran). The data was collected from 120 employees and by having separate questionnaire for Job satisfaction and OCB. They applied correlation, coefficient, Regression analysis to identify the relationship and degree of influence of one variable on the other. They found that there is a noteworthy positive association between job satisfaction and modules of OCB and one per cent change in job satisfaction positively increases 0.62 in OCB.

Sania Zahra Malik, Maheen Saleem, and Ramsha Naeem, (2016) examined the connexion between leadership styles and organizational citizenship behaviour in telecom industries operating in Pakistan. They applied Hierarchical multiple regression analysis and ANOVA to study impact of leadership style on OCB. They found that the majority rule administration style stimulated increasingly authoritative citizenship conduct among the representatives and imperious pioneer can't invigorate the sentiments of helping other people because of his errand situated nature. Moreover, Laissez faire administration style has an extremely powerless association with hierarchical citizenship conduct.

Sumi Jha, (2013) studied the originators of organizational citizenship behaviour (OCB) by taking transformational leadership and psychological empowerment. The research was conducted by taking a sample of 500 frontline employees working in nine five star hotels in Mumbai. The result shows that the associations create through the commitments of both pioneer and the subordinates. The directing impact of psychological empowerment had upgraded the connection between transformational administration and OCB and observed to be huge. This finding shows that subordinates' ability.

and sentiments of intensity help the pioneers to practice transformational administration for citizenship conduct.

Vijayabanu, et.al (2013) analyzed the link of OCB's six dimensions with job involvement by using Partial Least Square based Structural Equation Modelling (SEMThey presumed that Altruism and Conscientiousness have a optimistic relationship to OCB, and Civic Virtue, Recognition Practices and Procedural Justice Practice have no critical positive relationship towards OCB.

Yupono Bagyo, (2018) surveyed the employees working in an organisation to study the corruption which underline the performance undermines the performance of the organization. The researcher used Pearson correlation, multiple regression and path equation modelling to analyse the impact of CWB and Organizational Citizenship Behavior (OCB) on EP with Employee Engagement (EE) as mediating variable. The accentuation in this exploration is CWB in light of the fact that this frame of mind is a very inconvenience to the association and the national economy. Test outcomes demonstrate that the more noteworthy the CWB the exhibition diminishes. Be that as it may, after the Engagement variable is embedded the CWB negative impact is littler, this implies a representative ought to be urged to have a high OCB soul, in light of the fact that with OCB, the Engagement of workers increases. The outcomes demonstrated a critical connection between $\mathrm{OCB}, \mathrm{CWB}$ and $\mathrm{EE}$ on EP.

Zahra Gholami, et.al, (2013) conducted research by taking a sample of 224 public sector employees in Iran. They examined the relationship among the empowerment, commitment and OCB. They found that the there is a significant relationship among these variables.

Arif Partono Prasetio et.al. (2017) study identified the intervening job of authoritative duty in the connection between employment fulfillment and OCB. The examples were gotten from a review utilizing 39 things survey circulated to the 320 representatives of a state-possessed banking in Bandung, Indonesia. The result revealed organizational commitment mediated the relation of job satisfaction and OCB. Organization who wants their employees develop higher OCB, should focus on the human resources policy which related to the increase the work satisfaction and organizational commitment.

Ayesha Noor (2009) examined importance of OCB as the result of administrative commitment among the teachers in universities of Pakistan. The author studied the influence of training and growth openings, work-life policies and empowerment applies on organizational commitment. Data was collected from 134 teachers and the result revealed that training \& development opportunities, work-life policies and empowerment practices have noteworthy optimistic connection with organizational commitment.

Basharat Raza et.al (2017) study examined the direct relationship of administrative training with assignment execution and relevant execution, and circuitous relationship through interceding job of flourishing at work. Oneself planned polls were utilized to gather information from 280 representatives of pharmaceutical segment of Pakistan. The various leveled relapse investigation uncovers that administrative training legitimately impacts work execution, and in a roundabout way impacts work execution, authoritative citizenship conduct toward individual and association (OCBI-OCBO) too by means of interceding job of flourishing at work. The Sobel tests additionally affirmed and featured the hugeness of interceding job of flourishing at work in the theoretical model.

Jehad Mohammad et.al (2011) anlaysed the two extents of organisational citizenship behaviour with the two sides of job satisfaction (intrinsic and extrinsic). Survey method was used in this study. Information was gathered from the nonscholastic staff of Universiti Kebangsaan Malaysia. The outcome demonstrates that characteristic and extraneous occupation fulfillment was decidedly connected with the OCB.

Mahdiyar Rahro. (2013) investigated the relationships between Organizational citizenship behavior and five personality traits. The author investigated this by taking a sample 90 employees working in Hamkaran System Company. SEM was used to identify the influencing traits. The result found that personality traits like Extraversion and Sociability had significantly influenced OCB; however meticulousness, emotional stability and opening to experience had no significant effect on OCB.

Nahid Naderi, and Reza Hoveida (2013) attempted to distinguish the connection between authoritative citizenship behaviour (OCB) and human resource empowerment (HRE) among staff at University of Isfahan. Factual populace of the investigation was the majority of the staff in authoritative monetary, training social, and research areas at University of Isfahan. 
Illustrative insights and correlative technique for investigation was utilized for this examination. Mental strengthening and hierarchical citizenship conduct were the two markers that show there is an immediate and critical connection between and staff's Organizational citizenship behaviour (OCB).

\section{DATA AND METHODOLOGY}

The research uses 29 existing literature reviews researcher identified various variables of used in the study of OCB. Social Network Analysis that supports the analysis of the variables are visualised through Text Analytics software GEPHI 0.9.2 and NodeXL to understand the relationship among variables, visualisation of the connections of the variables and identify the most influencing variable as seen in the literature and to interpret the gap that could be addressed through new research. Researcher used various centrality measures viz Degree centrality, Closeness centrality, Betweenness centrality and In- degree, Out- degree centrality measures to analyse the data. Network connectedness to identify the most connected (strong) and the weak network thus identifying the most used variables and the least.

The nodes are the independent variables in the litereature and the dependent variables. A link is defined as the interaction of the two variables. As an example, if OCB was studied against empowerment and job satisfaction, this is considered as two links one from empowerment to OCB and the other from job satisfaction to OCB. This is constructed for the variables used inte study. The resultant network is considered as a directed network since the incidence is always from the independent variable to the dependent variable. The number of times a particular link is taken as the weight of the specific link. Since multiple studies could consider similar variables the network is a weighted directed network. Since the study is concerned with OCB most of the literature point to $\mathrm{OCB}$ as the dependent variable and hence it is expected that OCB would have a high level of connectedness in the network with high in degree.

\section{A. Degree Centrality}

Degree centrality the standardized grade centrality of every apogee and gives the general system degree centralization. The quantity of pinnacles contiguous a given vertex in a symmetric chart is the level of that vertex. For non-symmetric information the in-level of a vertex vi is the quantity of links gotten by vi and the out-degree is the quantity of links started by vi. Also, on the off chance that the information is esteemed, at that point the degrees (in and out) will comprise of the wholes of the estimations of the ties. The standardized degree centrality is the degree partitioned by the most extreme conceivable degree communicated as a percentage..

\section{B. Betweenness Centrality}

Node betweenness is the betweenness and standardized betweenness centrality of every vertex and gives the general system betweenness centralisation. The count depends on how frequently the node sits on the geodesic(shortest way) connecting two different nodes (on-screen characters) together. To calculate the Betweenness centrality, the following equation is used:
$\mathrm{Cb}(\mathrm{k})=\Sigma \mathrm{x}$ ijk/ $\mathrm{X} i \mathrm{j}, \mathrm{i} \neq \mathrm{j}, \mathrm{j} \neq \mathrm{k} . \mathrm{Cb}$ betweenness

centrality

Xijk - the number of shortest paths linking nodes $i$ and $j$ that pass through node $\mathrm{k}$;

$\mathrm{Xij}=$ the number of shortest paths linking. Betweenness centrality can be calculated for both directed and undirected graphs.

\section{IV - RESULT AND DISCUSSION}

The variables are plotted and the Figure -1 revealed the total no of nodes in the network is 58 and it has 74 unique edges with OCB having the most connections with all other variables in the network as expected. OCB has also been used as a independent variable on six different literature with 27 counts as the dependent variable. Organisational commitments, employee performance, OCBI, OCBO, and employee performance are the most considered variables. Job satisfaction, Empowerment, managerial coaching, thriving at work and both intrinsic and extrinsic satisfactions have been the most used variables for analysis as the independent effects. Moreover normative, continuance, affective and performance of OCBI and OCBO are variables not connected with the OCB.

Figure -2 (A, B, C) shows the connections among various variables associated with OCB. Degree centrality values are assigned to each variable based on their connection, highly connected variables getting high score and low connection variables are getting low values. OCB is getting

38 neighbour nodes, job satisfaction is having 5 , organisational commitment is having 6, managerial coaching, OCBI, OCBO, employee performance, having 4 points. All of these nodes only highly connected with OCB and all other nodes in the network are having less degree centrality. 
Developing Conceptual frame work for building Sustainable Organisation through Organisational Citizenship Behaviour

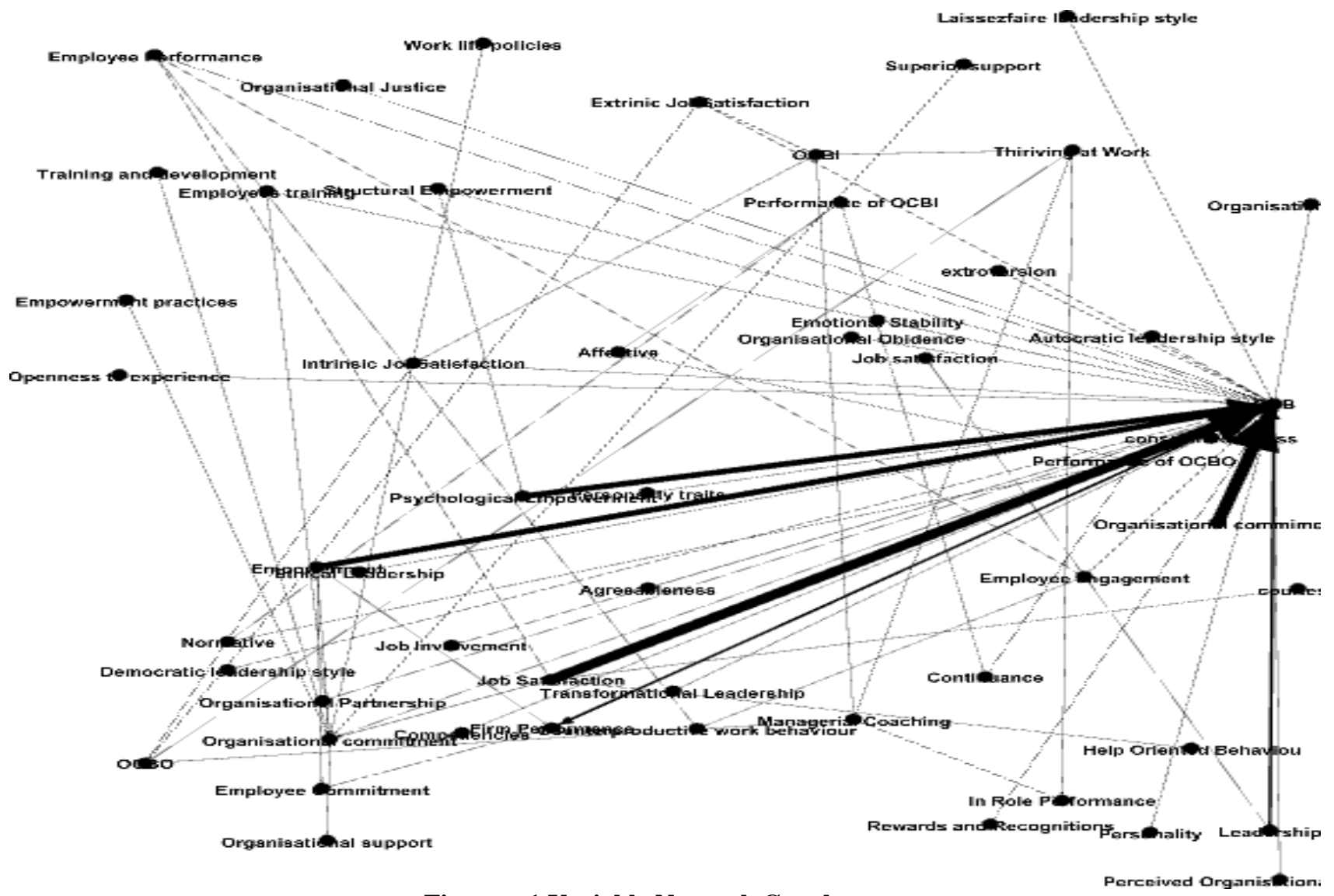

Figure - 1 Variable Network Graph

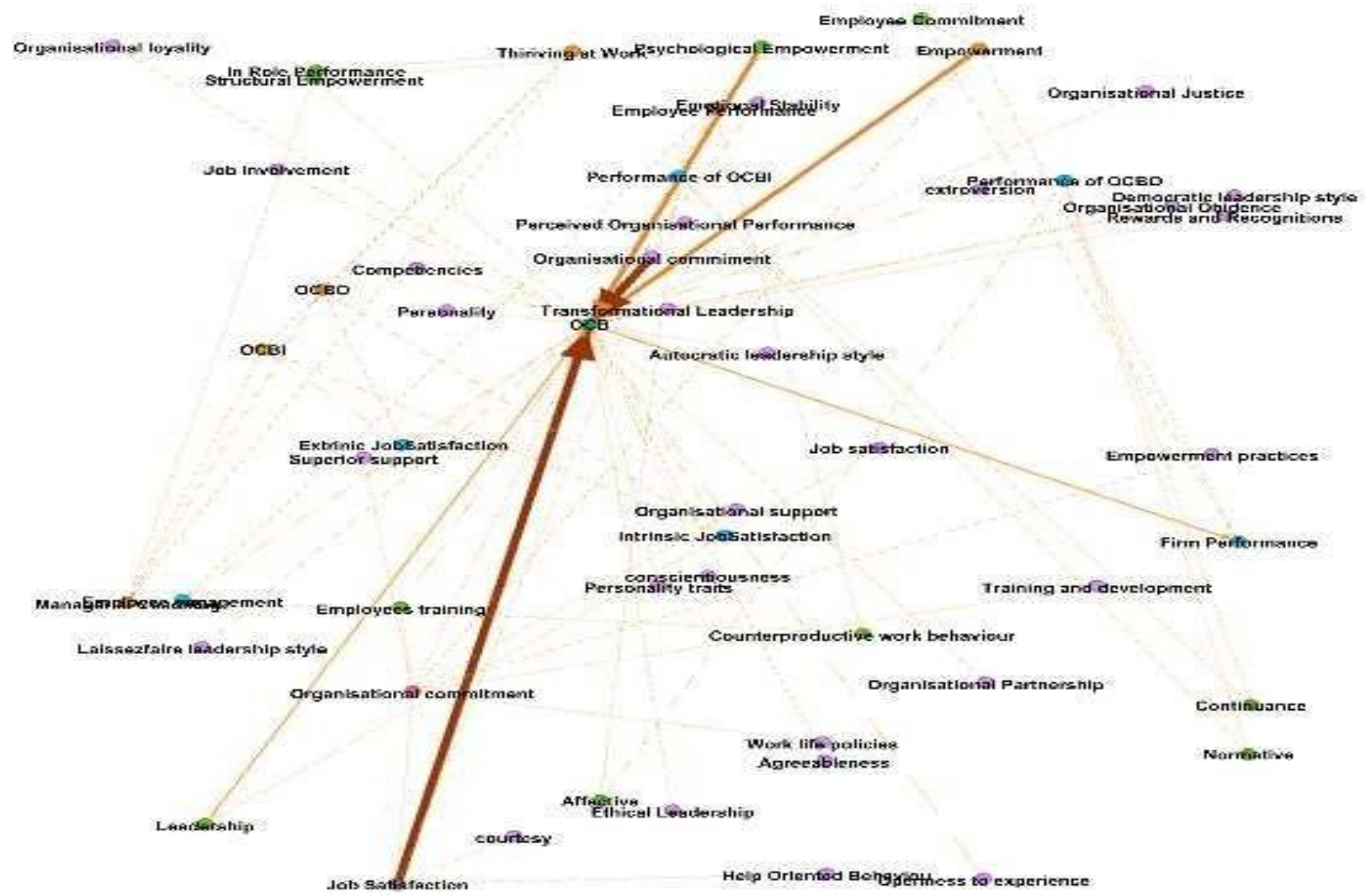

Figure - 2- A - Degree centrality 


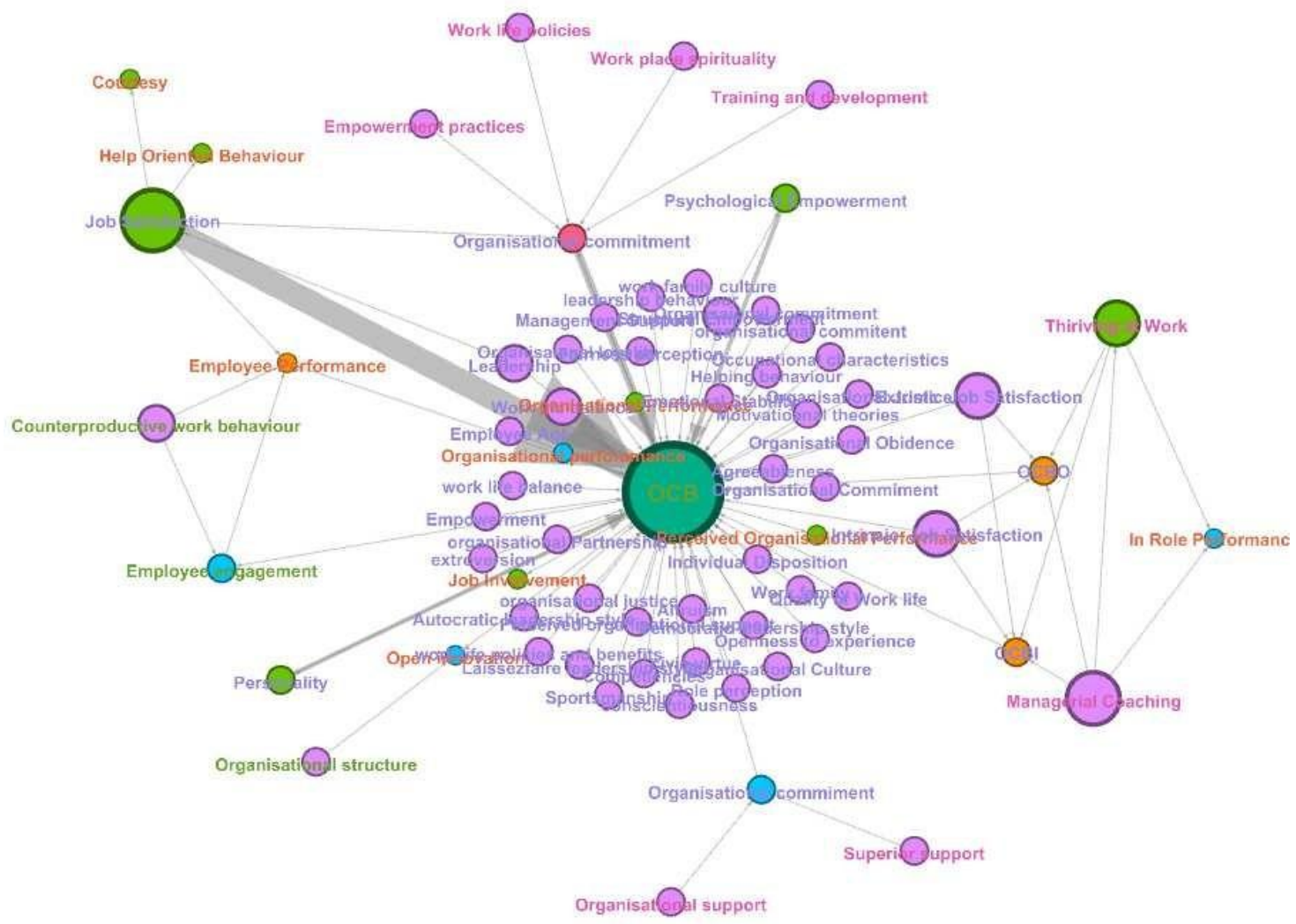

Figure - 2 -B - Indegree

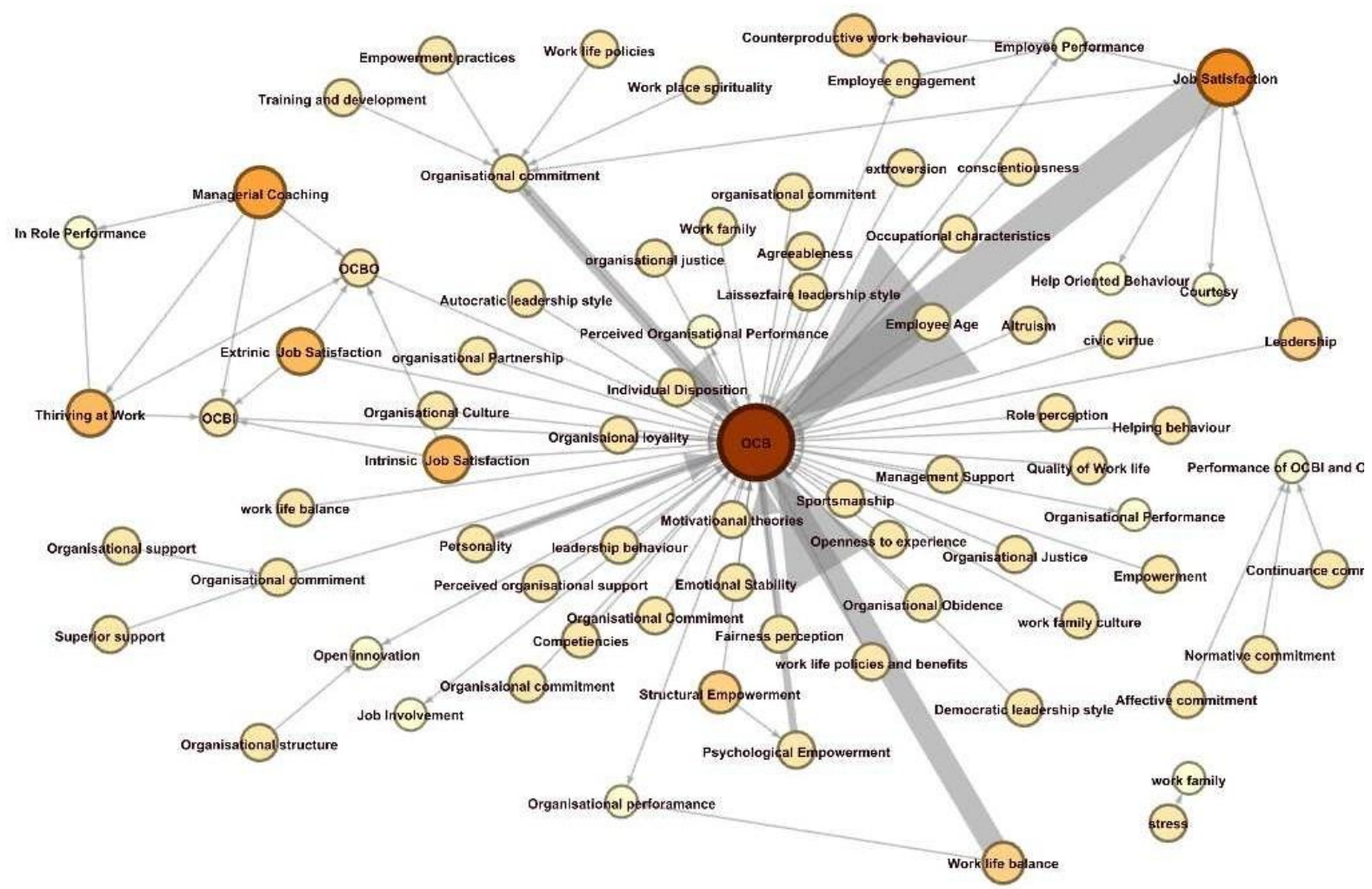

Figure - 2 -C - Out Degree 
Developing Conceptual frame work for building Sustainable Organisation through Organisational Citizenship Behaviour

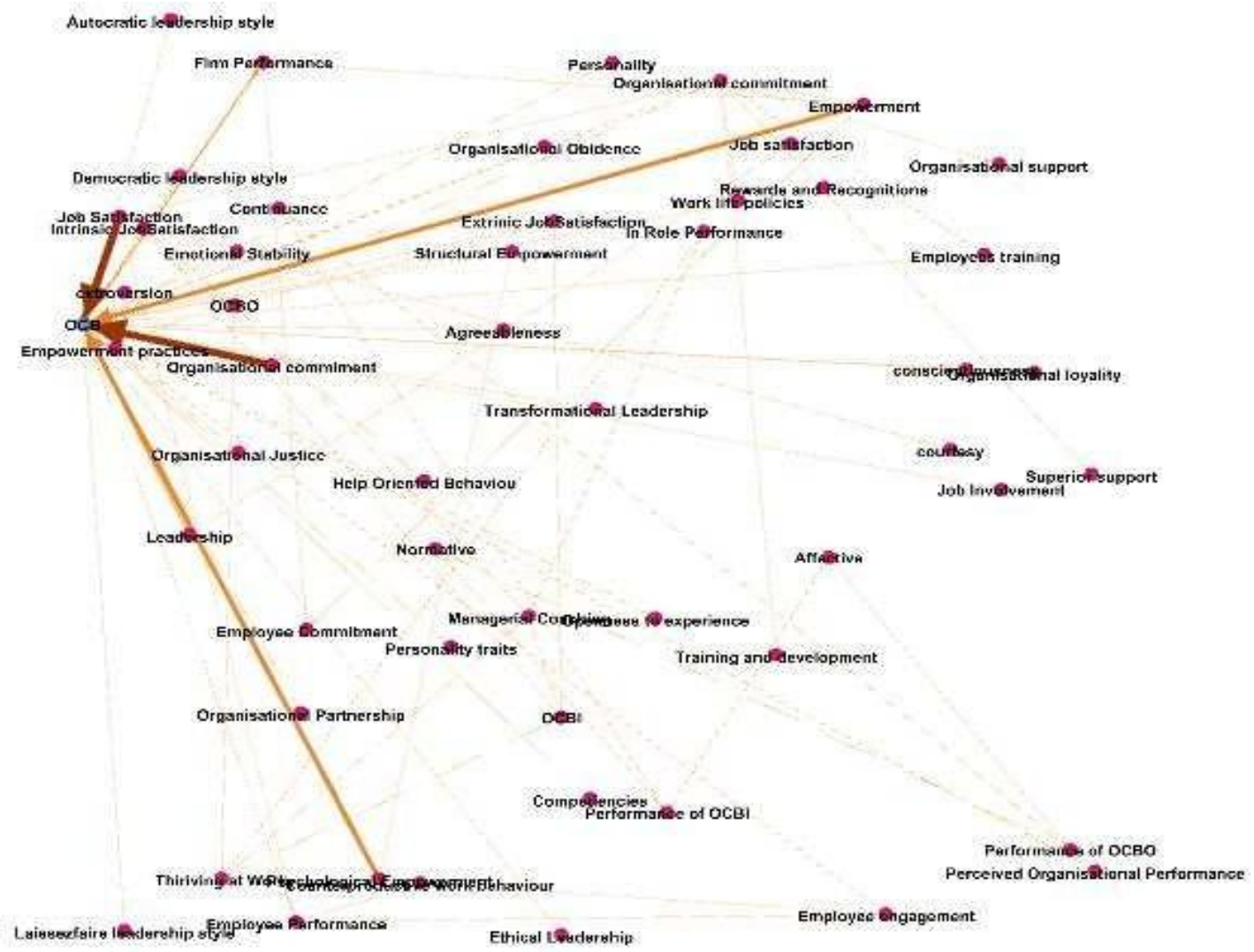

Figure - 3 Betweenness Centrality

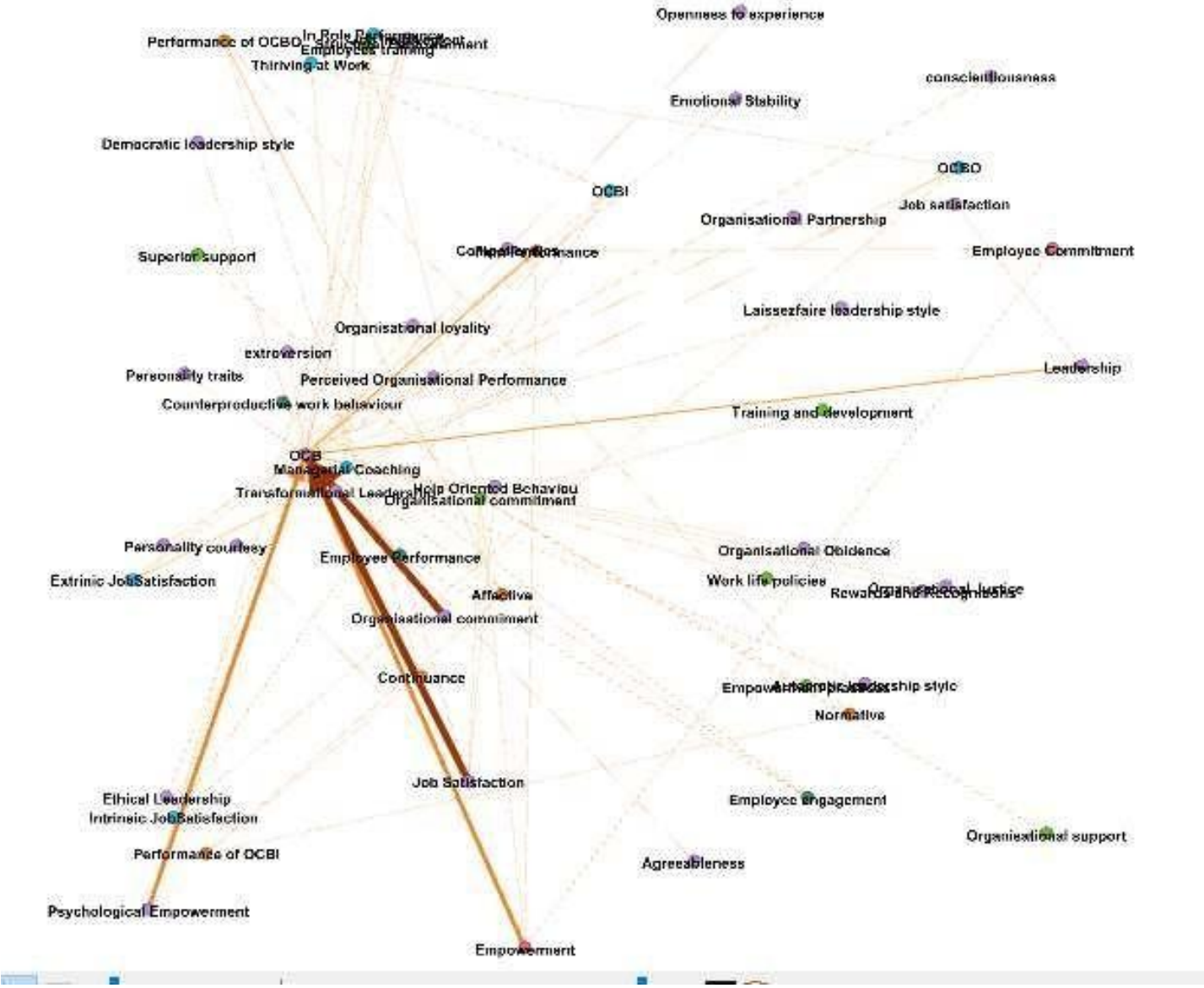

Figure - 4 - A- Modulairity.

$\mathrm{BC}$ measures the number of instances a node lies at the which nodes act as 'bridges' between noderiines shortest route among other nodes. This measure suggests 
community. It does this by means of figuring out all the shortest paths after which counting how typically every node falls on one. In Figure -3 OCB is having1363 shortest path in the network, job satisfaction is having 107 points Betweenness centrality. Organisational commitment is having 157.5 points, empowerment is having 78.5 points, intrinsic job satisfaction and extrinsic job satisfaction is having 120.25 points, OCBI and OCBO is having 75.33 points of between ness centrality. All the other variables are having very less connections only.

\section{MODULARITY}

Modularity is the degree to which a system components are made from notably unbiased additives or parts which may be blended. determine -four shows the modularity between the variables. here unique modules of the diagram are represented through values. Organisational citizenship behaviour of man or woman (OCBI) and organisational citizenship behaviour of organization (OCBO) is linked with extrinsic job satisfaction, intrinsic job satisfaction, thriving at work in role performance, managerial coaching. And another module is performance of OCBI and OCBO is linked with various commitment namely normative, continuances, affective (Figure-4-A). The module of the study shows that organisational commitment is linked with superior support and organisational support. Finally the fourth modularity of the study is job satisfaction, employee performance, employee engagement, counterproductive wok behaviour. So these are the relatively independent components. (Figure -4-B)

\section{GAP ANALYSIS AND FUTURE RESEARCH DIRECTIONS}

After assessing the literature on the theme individually and collectively, the researchers originate a enormous gap between the studies conducted till now and the real life problem. A more number of studies are showed in India as well as in foreign countries. There are many studies which show the combination of any two topics like eitherstudy on OCB and commitment, OCB and Job satisfaction, OCB and empowerment and many other allied issues. All these studies consider only a single term at a time or the combination of any two terms together. In the light of the above discussed gap it is clear that there is the need to study the relationship of organizational citizenship behaviour of organisation and individual variables like Emotional stability, Organisational obedience, organisational loyalty, employee training, thriving at work etc. Based on the review and gap the conceptual model is framed for future research (Figure5).

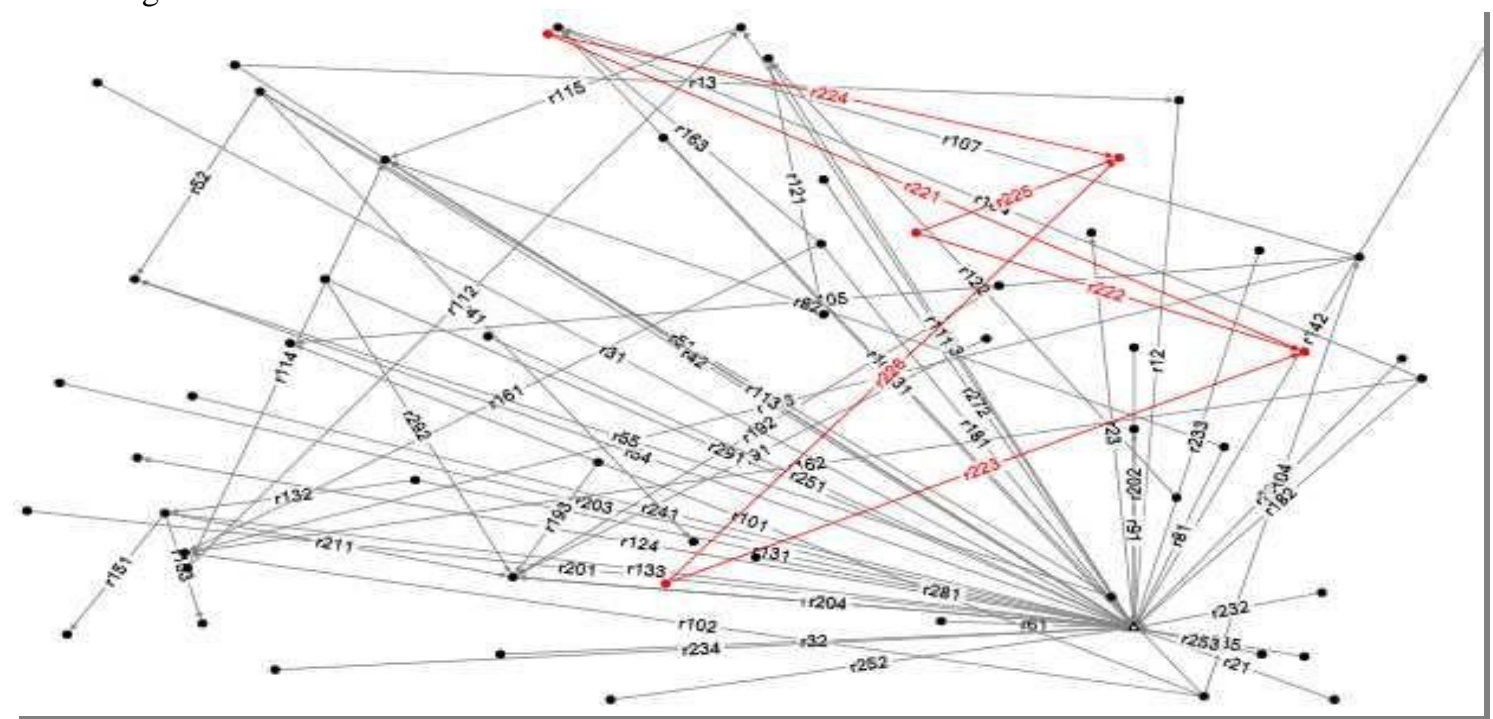

Figure - 5 Proposed model for OCB

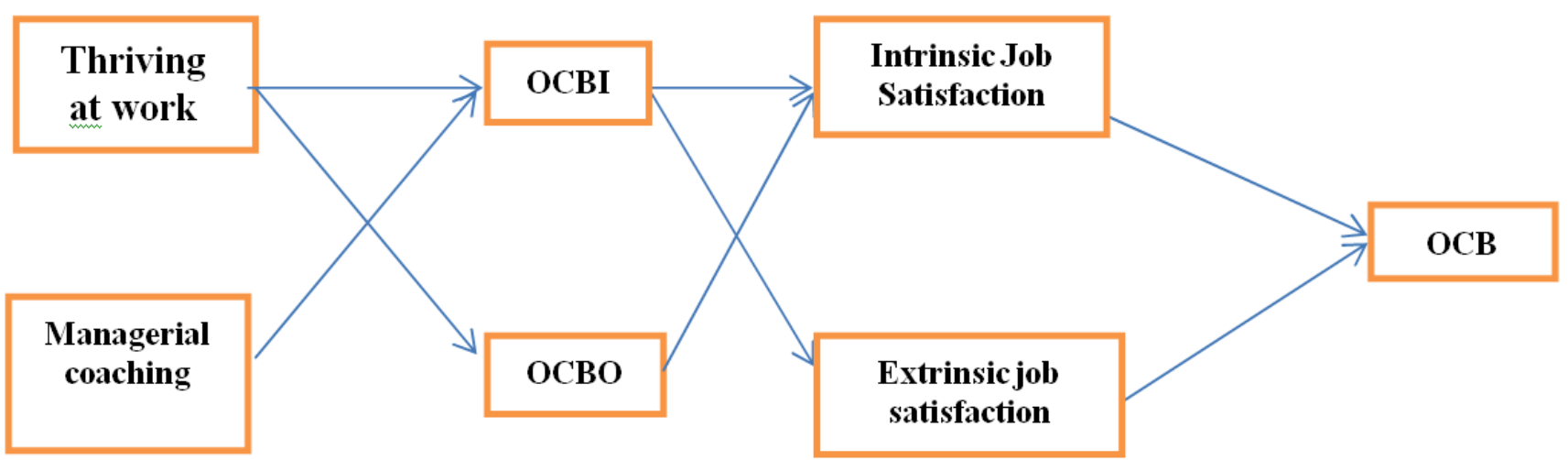

Table - 1 Result 
Developing Conceptual frame work for building Sustainable Organisation through Organisational Citizenship Behaviour

\begin{tabular}{|c|c|c|c|c|c|c|}
\hline Variable & In - degree & $\begin{array}{l}\text { Out - } \\
\text { degree }\end{array}$ & $\begin{array}{c}\text { Closness } \\
\text { Centrality }\end{array}$ & $\begin{array}{c}\text { Betweeness } \\
\text { centrality }\end{array}$ & $\begin{array}{c}\text { Modularity } \\
\text { Class }\end{array}$ & $\begin{array}{c}\text { Component } \\
\text { Number }\end{array}$ \\
\hline Affective & 0 & 2 & 1 & 0 & 0 & 0 \\
\hline Agreeableness & 0 & 1 & 0.538462 & 0 & 1 & 1 \\
\hline Autocratic leadership style & 0 & 1 & 0.538462 & 0 & 1 & 1 \\
\hline Competencies & 0 & 1 & 0.538462 & 0 & 1 & 1 \\
\hline Conscientiousness & 0 & 1 & 0.538462 & 0 & 1 & 1 \\
\hline Continuance & 0 & 2 & 1 & 0 & 0 & 0 \\
\hline \multicolumn{7}{|l|}{ Counterproductive work } \\
\hline Behavior & 1 & 0 & 0 & 0 & 1 & 1 \\
\hline Courtesy & 0 & 1 & 0.538462 & 0 & 1 & 1 \\
\hline Democratic leadership style & 0 & 1 & 0.538462 & 0 & 1 & 1 \\
\hline Emotional Stability & 1 & 1 & 1 & 0 & 4 & 1 \\
\hline Employee Commitment & 2 & 1 & 1 & 0 & 2 & 1 \\
\hline Employee engagement & 4 & 0 & 0 & 0 & 2 & 1 \\
\hline Employee Performance & 0 & 2 & 0.583333 & 0 & 3 & 1 \\
\hline Employees training & 0 & 4 & 0.666667 & 0 & 4 & 1 \\
\hline Empowerment & 0 & 1 & 1 & 0 & 3 & 1 \\
\hline Empowerment practices & 0 & 1 & 0.538462 & 0 & 1 & 1 \\
\hline Ethical Leadership & 0 & 3 & 0.6 & 0 & 5 & 1 \\
\hline Extrinsic Job Satisfaction & 0 & 1 & 0.538462 & 0 & 1 & 1 \\
\hline extroversion & 3 & 0 & 0 & 0 & 4 & 1 \\
\hline Firm Performance & 1 & 0 & 0 & 0 & 1 & 1 \\
\hline Help Oriented Behaviour & 2 & 0 & 0 & 0 & 5 & 1 \\
\hline In Role Performance & 0 & 3 & 0.6 & 0 & 5 & 1 \\
\hline Intrinsic Job Satisfaction & 1 & 0 & 0 & 0 & 1 & 1 \\
\hline Job Involvement & 0 & 5 & 0.692308 & 0 & 1 & 1 \\
\hline Job Satisfaction & 1 & 0 & 0 & 0 & 1 & 1 \\
\hline Job satisfaction & 0 & 1 & 0.538462 & 0 & 1 & 1 \\
\hline Laissez-faire leadership style & 0 & 2 & 0.571429 & 0 & 1 & 1 \\
\hline Leadership & 0 & 4 & 1 & 0 & 5 & 1 \\
\hline Managerial Coaching & 0 & 2 & 1 & 0 & 0 & 0 \\
\hline Normative & 27 & 6 & 1 & 157 & 1 & 1 \\
\hline $\mathrm{OCB}$ & 4 & 0 & 0 & 0 & 5 & 1 \\
\hline OCBI & 4 & 0 & 0 & 0 & 5 & 1 \\
\hline OCBO & 0 & 1 & 0.538462 & 0 & 1 & 1 \\
\hline Openness to experience & 0 & 1 & 0.538462 & 0 & 1 & 1 \\
\hline Organizational commitment & 9 & 0 & 0 & 0 & 3 & 1 \\
\hline Organizational commitment & 0 & 1 & 0.538462 & 0 & 1 & 1 \\
\hline Organizational Justice & 0 & 1 & 0.538462 & 0 & 1 & 1 \\
\hline Organizational loyalty & 0 & 1 & 0.538462 & 0 & 1 & 1 \\
\hline Organizational Obedience & 0 & 1 & 0.538462 & 0 & 1 & 1 \\
\hline Organizational Partnership & 0 & 1 & 1 & 0 & 3 & 1 \\
\hline \multicolumn{7}{|l|}{ Organizational support } \\
\hline perceived Organizational & 3 & 0 & 0 & 0 & 0 & 0 \\
\hline Performance & 3 & 0 & 0 & 0 & 0 & 0 \\
\hline Performance of OCBI & 0 & 1 & 0.538462 & 0 & 1 & 1 \\
\hline Performance of OCBO & 0 & 1 & 0.538462 & 0 & 1 & 1 \\
\hline Personality & 1 & 1 & 0.538462 & 0 & 1 & 1 \\
\hline Personality traits & 0 & 1 & 0.538462 & 0 & 1 & 1 \\
\hline Psychological Empowerment & 0 & 2 & 0.571429 & 0 & 1 & 1 \\
\hline Rewards and Recognitions & 0 & 1 & 1 & 0 & 3 & 1 \\
\hline Structural Empowerment & 1 & 3 & 1 & 0 & 5 & 1 \\
\hline Superior support & 0 & 1 & 1 & 0 & 3 & 1 \\
\hline Thriving at Work & 0 & 1 & 0.538462 & 0 & 1 & 1 \\
\hline Training and development & 0 & 1 & 1 & 0 & 3 & 1 \\
\hline
\end{tabular}

\section{CONCLUSION}

It is proved from the analysis that OCB is strongly connected with job satisfaction, organisational commitment, and empowerment, most of the studies are carried only between job satisfaction and OCB, OCB and Empowerment, OCB and organisational commitment, very minimum number of studies only showed among other

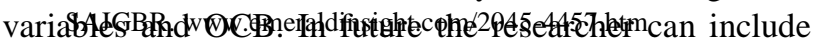

other variables namely employee training, managerial work life balance, in their study coaching, work life balance, in their study. 


\section{REFERENCES}

1. Azeem, M.M. Abrar, M. Bashir,M. and Zubair, A. (2015). "Impact of Organizational Justice and Psychological Empowerment on Perceived Organizational Performance. The Mediating Role of Organizational Citizenship Behaviour". American Journal of Industrial and Business Management. Scientific Research Publication, 272-280.

2. Anne Kariuki, Kellen Kiambati. (2017). "Empowerment, Organizational Commitment, Organizational Citizenship Behavior and Firm Performance." Management Studies, Vol. 5, No. 4, 290300, Kenya.

3. Arif Partono Prasetio et.al. (2017). 'Job Satisfaction, Organizational Commitment, and Organizational Citizenship Behaviour in State-owned Banking". Universal Journal of Management 5(1): 32-38, http://www.hrpub.org DOI: 10.13189/ujm.2017.050104.

4. Ayesha Noor (2009). "Examining Organizational Citizenship Behavior As The Outcome Of Organizational Commitment: A Study Of Universities Teachers Of Pakistan". Proceedings 2nd CBRC, Lahore, Pakistan

5. Basharat Raza.et.al. (2017). "Impact of Managerial Coaching on Employee Performance and Organizational Citizenship Behavior: Intervening Role of Thriving at Work". Pakistan Journal of Commerce and Social Sciences, Vol. 11 (3), 790-813

6. P. David Jawahar. Samanvitha Swaminathan . (2013). "Job Satisfaction As A Predictor Of Organizational Citizenship Behavior: An Empirical Study". Global Journal Of Business Research , Volume 7. Tiruchirapalli, India.

7. El Din Mohamed WS. (2016). "Investigating the Relationship between Job satisfaction and Organizational Citizenship Behavior." Arabian Journal of Business and Management Review. ISSN: 2223-5833.

8. Gülsevim Yumuk Günay. (2018). "Relationship between Job Satisfaction, Organizational Citizenship Behavior and Employee Performance". American International Journal of Contemporary Research., Vol. 8, No. 1, Turkey.

9. Jency Priyadharshany.A and Sujatha.S. (1997). "Empowerment and Organisational Citizenship Behaviour: A Mediation Analysis". Man In India, 77-91, Serials publication. Chennai

10. Jehad Mohammad et.al (2011). "Job Satisfaction And Organisational Citizenship Behaviour: An Empirical Study At Higher Learning Institutions". Asian Academy of Management Journal, Vol. 16, No. 2, 149-165.

11. Kaveh Hasani.et.al.(2013). "The effect of organizational citizenship behaviour on organizational commitment". International Network of Business and Management.Glob Bus Perspect, 1:452-470, DOI 10.1007/s40196-013-0026-3.

12. Lara Priyadharshini Sinnappan. Mahadevan Amulraj. (2014). "Impact of Rewards and Recognition and Empowerment on Organizational Citizenship Behaviors among Technical Engineers". Management Studies and Economic Systems (MSES), 1 (2), 89-95, ZARSMI.

13. Mirza Muhammad Azeem et.al (2015). "Impact of Organizational Justice and Psychological Empowerment on Perceived Organizational Performance: The Mediating Role of Organizational Citizenship Behaviour". American Journal of Industrial and Business Management, 5, 272-280, Scientific research pulication.

14. Mahdiyar Rahro. (2013). "Identification of Personality Traits Affecting on Development of Organizational Citizenship Behavior." Middle-East Journal of Scientific Research 16 (2): 274281, ISSN 1990-9233.

15. Nahid Naderi, and Reza Hoveida (2013). "The relationship between Organizational Citizenship Behavior (OCB) and Human Resources Empowerment (HRE) Case study: University of Isfahan". International Journal of Human Resource Studies, ISSN 2162-3058, Vol. 3, No. 2

16. Pratami Wulan Tresna. (2016). "The Influence of Transformational Leadership to Organizational Citizenship Behavior with Job Satisfaction as Mediator Variable." Review of Integrative Business and Economics Research, Vol. 5, no. 2, pp.295-303, ISSN: 2304-1013 (Online); 2304- 1269 (CDROM); 2414-6722.

17. Rahil Kazemi Talachi (2014). "An Investigation of the Role of Job Satisfaction in Employees’ Organizational Citizenship Behaviour.
Original scientific paper." Coll Antropol. 38 2: 429-436

18. Seonghee Cho. Johanson, M. (2008). "Organizational Citizenship Behavior and Employee Performance: A Moderating Effect of Work Status in Restaurant Employees." Journal of Hospitality \& Tourism Research • DOI: 10.1177/1096348008317390.v Georgia.

19. Sumi Jha. (2013). "Transformational leadership and psychological empowerment Determinants of organizational citizenship behaviour".

20. C. Vijayabanu. K. Govindarajan. R. Renganathan. (2013). "Organizational Citizenship Behavior And Job Involvement Of Indian Private Sector Employees Using Visual Pls-Sem Model". UDC 005.32.

21. Yupono Bagyo.(2018). "The Effect of Counterproductive Work Behavior (CWB) And Organizational Citizenship Behavior (OCB) on Employee Performance With Employee Engagement As Intervening Variable.”. IOSR Journal of Business and Management (IOSR-JBM), e-ISSN: 2278-487X, p-ISSN: 2319-7668. Volume 20, Issue 2, Indonesia.

22. Zahra Gholami, Javad Abdeli Soltanahmadi, Ghasem Pashavi and Sedigheh Nekouei. (2013)." Empowerment as a Basic Step in Upgrading Organizational Commitment and Organizational Citizenship Behaviors: A Case Study on Public Sector in Iran". World Applied Sciences

\section{AUTHORS PROFILE}

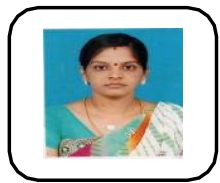

Ramalakshmi Krishnan, Research scholar, Kalasalingam business school, Department of Business Administration, Kalasalingam university, Krishnan kovil.

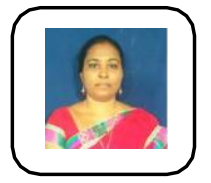

Anil Chandrasekaran holds a $\mathrm{PhD}$ in Econometrics and Business Administration with masters in Engineering and Business with an extensive experience in both the industry and academia. His research interests are in the areas of Social Network Analysis from an applied perspective to Operations, Marketing and Finance. Working as a professorial faculty in Higher Colleges of Technology teaching mainly the Quantitative courses in Statistics and Operations Research for both the engineering and business programs. He has an active industrial collaboration as a consultant for quality improvement and business data analytics.

SelvaraniMariappanis currently working in Kalasalingam Business School, Kalasalingam Academy of Research and Education (Kalasalingam deemed to be University). She completed MBA from MepcoSchlenk Engineering College, India and ICWA Inter. She obtained her Doctorate from Kalasalingam University and is a researcher and teacher in the area of finance for more than 16 years. She expertise in stock market behavioral research and underwent FDP program on Econometrics in IIM, Kozhikode and published more research papers in a SCOPUS indexed journal and reviewer of finance journals. She contributed her research work as chapters in books. She writes extensively and presented papers in International and National Conference organised by IIT, IIM's and publishes scholarly works and case study. She got trained by Infosys on Global Business Foundation Skill and NIT on Analytics. She conducted FDP, Workshop and gave guest lecture to Students, employees and research Scholars. She acted as a BOS member for SFR College, Sivakasi. She got awards for her competency in teaching for two times and faculty advisory ship from IQAC, KARE. 